\title{
Standards for quality assurance of pre-employment medical examinations of seafarers: the IMHA Quality experience
}

\author{
Tim Carter ${ }^{1}$, Sally Bell ${ }^{2}$, Alf Magne Horneland ${ }^{1}$, Suresh Idnani ${ }^{3}$ \\ ${ }^{1}$ Norwegian Centre for Maritime Medicine, Haukeland University Hospital, Bergen, Norway \\ ${ }^{2}$ Former Secretary IMHA Quality, United Kingdom \\ ${ }^{3}$ Medical Consultant, MASSA Maritime Academy (affiliated to DG Shipping), India
}

\begin{abstract}
Standards to assess the quality of doctors and clinics performing pre-employment medical examinations (PEMEs) were developed for International Maritime Health Association (IMHA) Quality, a not for profit organisation, created to provide an ethically sound and professional accepted accreditation system that would benefit seafarers having PEMEs and employers, insurers and national maritime authorities seeking valid assessments of seafarers' fitness for duty. These standards followed a format widely used in other healthcare settings, where assessment of clinical performance is desirable.

Uptake of these standards by doctors and clinics was not as expected, as they did not see sufficient business benefits coming from accreditation to justify the costs. This was, at least in part, because there was some antagonism to a professionally based accreditation system from commercial interest groups such as insurers, while national maritime authorities did not come forward to use the system as a recommendation or requirement for approval of doctors.

The IMHA Quality accreditation system has now been closed and for this reason we are making the standards publicly available. Those who helped to develop them hope that doctors and clinics will now use them as a means of improving the quality of their practice when performing PEME.
\end{abstract}

(Int Marit Health 2017; 68, 2: 99-101)

Key words: pre-employment medical examinations, seafarers, quality assurance, accreditation

\section{INTRODUCTION}

Seafarers require a statutory medical certificate in compliance with the requirements of the International Labour Organisation (ILO) Maritime Labour Convention 2006 and the International Maritime Organisation (IMO) Standards of Training, Certification and Watchkeeping (STCW) Convention, as amended 2010 [1, 2]. In addition many employers and insurers have additional medical fitness requirements specified in company policies. Seafarers are recruited globally but only a minority of national maritime authorities exercise any supervision over the conduct of performing pre-employment medical examinations (PEMEs) that lead to issue of statutory certificates in their name. For this reason employers and insurers have, over the last 20 years, introduced their own standards and approval systems for the clinics that they use to assess the medical fitness of crewmembers serving on the ships they operate or insure.

A single doctor or a clinic, especially one assessing crew for service on ships registered in countries other than the one where the clinic is located, may have multiple audits by different bodies, each with different approaches and requirements. Alternatively they may continue to issue certificates of dubious validity without any oversight. Sometimes there may even be corrupt business or ethical practices.

An International Maritime Health Association (IMHA) consensus workshop was held in 2006 to consider the need for an initiative on improving quality assurance for

Dr Tim Carter, Norwegian Centre for Maritime Medicine, Haukeland University Hospital, Bergen, Norway, e-mail: tim.sea@doctors.org.uk 
PEMEs [3]. A staged approach to development was proposed, with the first stage being the commissioning a recognised healthcare accreditation organisation to develop a set of criteria for doctor and clinic assessment and accreditation. Healthcare-specific standards were needed because the ISO system of standard setting and accreditation is seen as having significant limitations as a means of quality assurance for clinical tasks.

Funds were needed for this initial work but it was recognised that any accreditation scheme in maritime health would need to eventually become self-funding, either through fees charged to clinics/doctors for accreditation or by payments made by organisations such as maritime authorities, insurers or employers who value quality assured certification systems.

\section{DEVELOPMENT OF STANDARDS AND ACCREDITATION}

IMHA received funding from the TK Foundation, a major maritime trust fund, to cover the costs of developing standards and related requirements [4]. CHKS, an international healthcare quality assurance organisation, was commissioned to work with a sub group of IMHA members to develop standards and to train assessors [5].

Standards covered (see Appendix - journal website, supplementary file):

1. Clinic management

2. Policies and procedures

3. Staff

4. Complaints

5. Clinic facilities

6. Health and safety

7. Infection control

8. Information technology

9. Finance

10. Clinical practice

11. Health records

12. Laboratory services

13. X-ray services

14. Immunisation service

15. Pharmacy service

16. Audit and quality improvement

Overarching requirements, such as client relationships, confidentially and professional ethics were imbedded within several of these standards.

Based on discussions with potential beneficiaries of the accreditation system it was recognised that such a service would best be provided by a free standing not for profit organisation rather than by a professional association that could be seen as trying to obtain benefits exclusively for its members. To meet this preference 'IMHA Quality' was set up as an independent charity registered under English law, with trustees from a range of interest groups in the maritime sector. The formal object of the charity was: 'To improve the quality and effectiveness of the interventions used to prevent and treat illness in seafarers or to improve their safety. These include assessment, evaluation and research on the importance of different risks to seafarers' health and on the provision of maritime health services.' A subsidiary operating company was formed to deliver audits of quality assurance and to accredit clinics/doctors who met quality assurance standards.

An initial group of assessors was trained by CHKS staff. It was envisaged that the trained assessors would be involved in assisting those who joined the scheme to introduce progressive quality improvements in their practices until they reached the point of meeting the core requirements in the standards. They would then be audited and be able to progress towards accreditation by introducing those additional aspects of the standards that were appropriate to their situation and client base.

Supporting IT systems for the management of all aspects of the accreditation process from applications to join through to issue of a certificate of accreditation were also developed. These provided IMHA Quality with up to date information on the status of participants, assessors and finances as well as being a source for information to those considering joining or wishing for advice and assistance as they moved towards accreditation.

\section{INTRODUCTION OF IMHA QUALITY ACCREDITATION}

Once the development of standards had been completed and they had been used on a trial basis at a selection of clinics, IMHA Quality was launched during a maritime health conference in Manila on $25^{\text {th }}$ October 2012. This event gave the first warning of problems ahead, as a number of attendees, particularly those associated with P\&I Clubs and with crewing agencies and repatriation services, questioned the need for the initiative. They pointed out that they already had arrangements in place that met their needs and saw IMHA Quality as threatening their relationships with clinics, which they saw as sub-contractors, by creating a parallel set of quality criteria that might not fully accord with their own. Some clinics based in the Philippines questioned the costs of the system, pointing out that some aspects duplicated quality requirements for clinics in the Philippines that were also specified by the Department of Health.

Consideration was given to a marketing strategy prior to and at the time of the launch. However, with hindsight, there was insufficient critical input to this on the barriers to introducing an accreditation scheme and the feasibility of overcoming them, given the costs of the scheme and the sectional interests of those likely to create such barriers. 
Initially a good number of clinics signed on to the IMHA Quality IT system to find out more and to register an interest in accreditation but the numbers who followed this up by committing to start the quality assurance process leading to accreditation was disappointing. Enquiries revealed that clinics were viewing accreditation solely on a costs and benefits basis and that most had taken the view that, unless they could be sure of at least recovering the costs of accreditation from increased revenue from PEMEs, there was no justification for starting the accreditation process. These views may have been aided by the lack of commitment from national maritime authorities to endorse participation as a condition of approval. For those authorities that considered this, the common concern was about giving a monopoly for accreditation to a single body, something that would be inevitable given that there were no alternatives available. There was also some suggestion that the commercial interests listed above were briefing clinics negatively about the consequences from participation on their future business dealings.

\section{SUBSEQUENT DEVELOPMENTS}

The STCW 2010 amendments included a requirement for maritime authorities to have quality assurance approaches in place that covered a range of aspects of certification, including issue of medical certificates [6]. This could have provided a new opportunity for IMHA Quality standards to be adopted, but for most authorities quality assurance of medical certification was a low priority and those that did look at this seriously tended to assume that ISO standards would be adequate for the task. However, as noted, other parts of the healthcare system have found that ISO standards do not adequately address the quality of clinical care.

When it became apparent that a self-funding system for the provision of accreditation of doctors and clinics for conduction PEMEs would not be viable the trustee of the charity considered that they had no alternative to closing both the charity and the operating company. They also felt that it would be appropriate to place the quality standards developed for the conduct of PEMEs in the public domain so that maritime health practitioners and those who commission services from them will be able to access and use them for the benefits of the seafarers they examine and for the benefit of all interests in the maritime sector as this was in accord with the charitable object of IMHA Quality. The standards are attached as an appendix to this article.

\section{CONCLUSIONS}

The IMHA Quality initiative was developed in a spirit of idealism to meet what its protagonists saw as gap in the arrangements for ensuring that seafarers were validly, consistently and ethically assessed prior to embarkation. It did not succeed, or was an idea in advance of its time, because the costs were seen as disproportionate to the business benefits. This was exacerbated by a negative attitude or by indifference by those parts of the maritime sector that would, in the long term, benefit from quality assured PEMEs being widely available.

\section{REFERENCES}

1. Maritime Labour Convention 2006, International Labour Organisation, Geneva. Regulation 1.2, Code A1.2.

2. International Convention on Standards of Training, Certification and Watchkeeping for seafarers, 1978, as amended. International Maritime Organisation, London 2011. Regulation 1/9.

3. The application of quality assurance schemes to maritime health care. IMHA working group meeting, Mumbai 31 March 2006. http:// imha.net/images/stories/IMHA\%20Workshop\%20Report\%20 -\%20Mumbai\%202006(1).pdf (last accessed 20 Oct 2016)

4. TKFoundation. http://www.tkfoundation.bs (accessed 5 December 2016).

5. CHKS. http://www.chks.co.uk (accessed 5 December 2016).

6. International Convention on Standards of Training, Certification and Watchkeeping for seafarers, 1978, as amended. International Maritime Organisation, London 2011. Regulation 1/8. 